\title{
Belief and Policy Influencing Nurses in Implementing Kangaroo Mother Care: A Systematic Review
}

Yuliati

Faculty of Public Health, Universitas Indonesia, Depok, Indonesia

\section{Abstract}

5.9 million child deaths occurred in 2015, almost 1 million happened in the first day of life, and close to 2 million took place in the first week (UNICEF 2014). Respiratory distress syndrome, hypothermia, and sepsis were the leading causes of death among newborns. Kangaroo Mother Care (KMC) for Low Birth Weight (LBW) in a community can improve survival, especially where the access to health facilities is limited. Although nurses play an essential role in implementing KMC in the community, there is limited systematic information available on the factors that are influencing nurses in implementing KMC. This systematic review sought to identify the most frequent factors affecting nurses

Corresponding Author:

Yuliati

yuliatiahmad7@gmail.com

Received: 26 December 2018 Accepted: 23 February 2019 Published: 7 March 2019

Publishing services provided by Knowledge E

(c) Yuliati. This article is distributed under the terms of the Creative Commons

Attribution License, which permits unrestricted use and redistribution provided that the original author and source are credited.

Selection and Peer-review under the responsibility of the $2 \mathrm{nd}$ International Meeting of Public Health 2016 Conference Committee.

\section{G OPEN ACCESS} in implementing KMC. This study relies on PRISMA. We searched three electronic databases and relevant reference lists for publications reporting factors influencing nurses in implementing KMC. We identified 938 unique publications, of which 104 were included based on pre-specified criteria. Publications scanned for all factors affecting nurses in implementing KMC. Each paper was also categorized based on its approach to the identification of barriers. The remaining 15 articles spanning six years (2011-2016) included in this review. We identified factors that influence nurses in implementing kangaroo: the attitude of nurses is ambivalent, lack of knowledge, belief, lack of infrastructure, the physiological stability of baby, lack of standard operational procedures, lack of skills, institutional leadership and lack of policy. Three of the top-ranked factors influencing KMC practice for nurses were: belief, lack of policy and lack of standard operational procedures (SOP).

Keywords: Kangaroo Mother Care (KMC); nurses; barrier; policy; belief

\section{Introduction}

The first 28 days of life, the neonatal period is the most vulnerable time for a child's survival. The global neonatal mortality rate in 2015 was 19 deaths per 1.000 live births. Over the same period, the number of newborn babies who died within the first 28 days of life was 2.7 million. This pattern applies to most low- and middle-income countries. Of the estimated 5.9 million child deaths in 2015, almost 1 million occur in the first day of life and close to 2 million take place in the first week (UNICEF 2014) Respiratory distress 
syndrome, hypothermia and sepsis were the leading causes of death among newborns (Abdalla and Ali 2015).

Kangaroo mother care is a complex intervention with several possible components skin-to-skin contact, breastfeeding, early discharge, and follow-up. The included components varied across locations and by individual implementer(Engmann et al. 2013). $\mathrm{KMC}$ for low birth weight newborns in community settings may greatly improve survival, especially where access to health facilities is limited. In low birth weight newborns $(<$ $2000 \mathrm{~g}$ ) who are clinically stable, kangaroo mother care reduces mortality and if widely applied could reduce deaths in preterm newborns (Chan et al. 2016). Research from various countries also suggests that KMC is a cost-effective method for treating preterm infants, mothers who have practiced KMC may find it acceptable (Seidman et al. 2015). However, in spite of the evidence, country-level adoption and implementation of kangaroo mother care have been limited and global coverage remains low (Chan et al. 2016).

Many studies discuss the barriers and enablers of KMC (Abdalla and Ali 2015; Chan et al. 2016; Seidman et al. 2015), but There is limited systematic information available on the factors influencing nurses in implementing KMC. This review set out to synthesize existing literature on the factors that affect nurses in performing $\mathrm{KMC}$ by answering questions, what are the most frequently cited barriers that could prevent nurses from successfully implementing KMC? These barriers can exist at multiple levels, including barriers to implementation of KMC program, deficiencies in the program itself, or specific challenges associated with the practice of KMC which the nurses must perform. Even though the particular barriers most relevant for nurses may vary based on context, a comprehensive list of this type will give program implementers and researchers a synthesized set of factors to consider as they attempt to implement new or improve existing KMC programs.

\section{Methods}

This study relies on the Preferred Reporting Items for Systematic Review and MetaAnalyses Statement (PRISMA). The authors searched Scopus, Pro Quest, and the World Health Organization's regional databases, for studies on "kangaroo mother care" or "kangaroo care" or "skin-to-skin care" from Jan 2011 to February 2016, without language restrictions. We included relevant reference lists for publications reporting barriers or enablers to KMC practice. We identified 938 unique publications, of which 104 were added based on pre-specified criteria. Each paper was also categorized based on its approach to identification of barriers/ enablers and nurses assigned to publications 
which had systematically sought to understand factors influencing nurses in KMC practice. The remaining 15 articles spanning a 6-year period (2011-2016) included in this review.

The data source is selected based on the title, abstract and full-text paper that match the keywords that have been assigned, published in English. The inclusion criteria used in this study included journals that have been reviewed by experts, describes the factors influencing nurses in implementing KMC. Dissertations and these excluded from this study.

Based on this search strategy, our findings included many studies which had observational information on factors influencing nurses in implementing KMC. Given the limited amount of synthesized information on barriers to KMC practice, we felt it was important to include these observational findings so that relevant programmatic experience informed this review.

Each study was placed into one of these categories independently by one reviewer, in our findings and discussion, we refer to "top-ranked" factors influencing nurses in implementing KMC. Top-ranked factors are affecting nurses in implementing KMC that received the highest score based on this indexed ranking, which accounts for both frequencies of mention across publications and weighting of each piece of evidence based on the publication type. To understand factors influencing nurses in implementing kangaroo mother care we created a narrative analysis of the articles and reports identified, guided by a green model.

There are some limitations to this assessment. This study aimed to synthesize existing literature on factors influencing nurses in implementing KMC. As noted, there are some limited systematically organized information on this topic. Therefore, to ensure that our review captured as many relevant qualitative and quantitative findings as possible, we choose to include any study identified through our search strategy which had information on factors influencing nurses in implementing KMC, even if studying this topic was not

the primary purpose of the publication. The article inclusion is small, taken from 15 articles.

\section{Results}

The articles were mostly international journals relevant to the theme of research and design of the type of systematic review, open interviews, observation, and competency assessment. Researchers used 15 literatures that almost all medical journals and bulletin of the World Health Organization. Of the 104 papers identified, we included 15 studies 
with qualitative data on barriers to and enablers of kangaroo mother care - the studies published between 2011 and 2016.

The samples used were a scientific journal that searched in journal databases. Chronology of the sample data selection can be seen in the flowchart below:



15 Articles included in the qualitative analysis

89 Fulltext article excluded (not discussed barrier or full-text article not found)

Figure 1: Flowchart showing the selection of studies on kangaroo mother care (KMC).

Using incubators for LBW babies is costly, and there are a limited number of nurseries available in many health centers. The warmth of the mother's body turned out to be a useful source of heat for babies born premature or low birth weight. This occurs when there is direct contact between the mother's skin and the baby's skin. This principle is known as skin to skin contact or kangaroo mother care (KMC) (Ludington-Hoe RN, CNM, Ph.D., FAAN 2011). This method is useful for premature babies to help restore a result of prematurity and maintain parents to be more confident and be able to play an active role in caring for their baby (Malhotra et al. 2014). Kangaroo method role in newborn care humanely improves the bond between mother and baby.

However absorption KMC as a routine practice so slow (Kymre n.d.). Many studies of the KMC method showed the barriers in implementing it. Mother, father, and family are usually the primary caregivers of premature newborns and involved in decision making and care practices (Nyqvist 2016). Health practitioners play an essential role in implementing the KMC in hospitals or health care facilities (Gabriel Seidman et al. 2015). Their primary purpose is to educate parents about the KMC. 

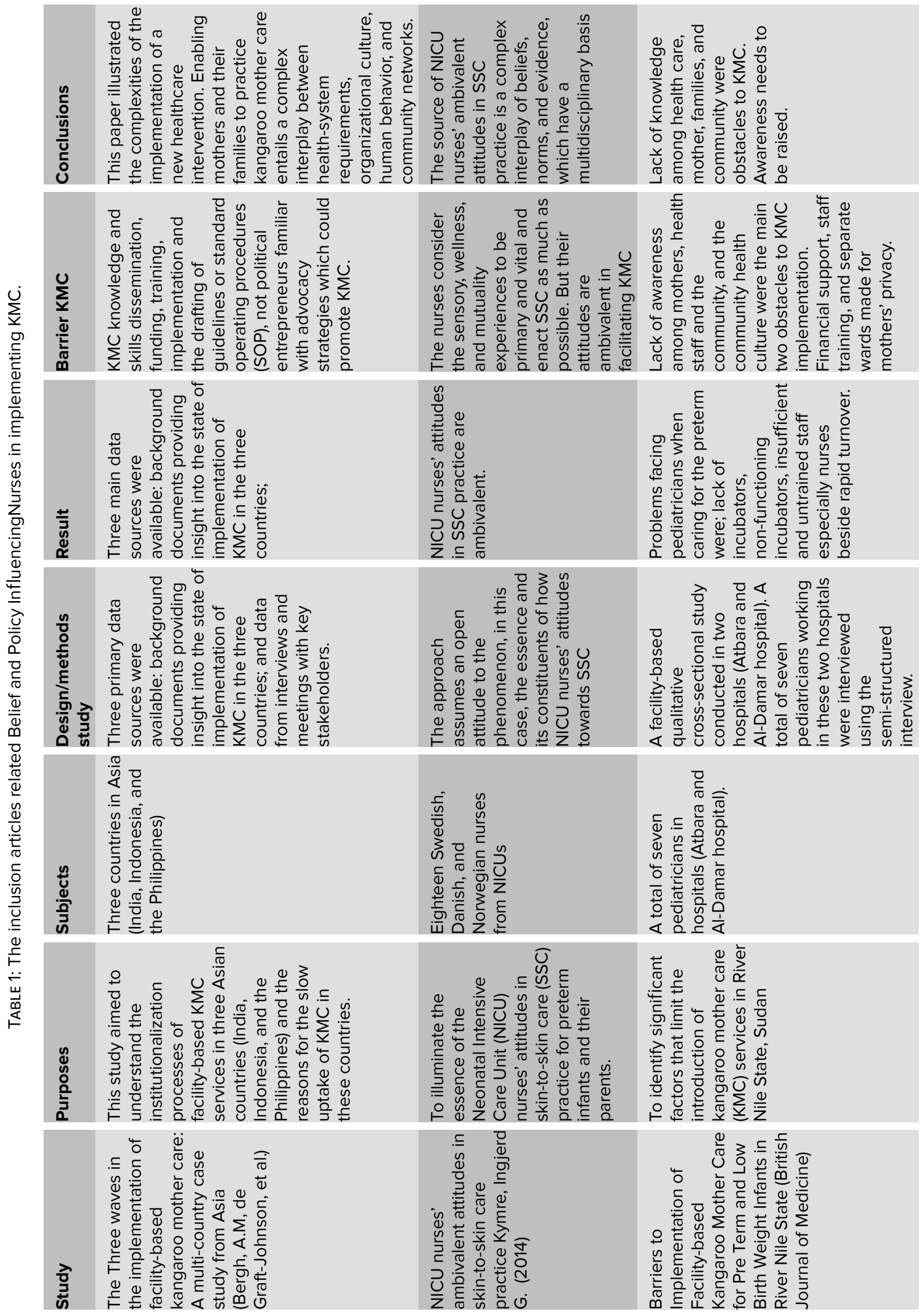



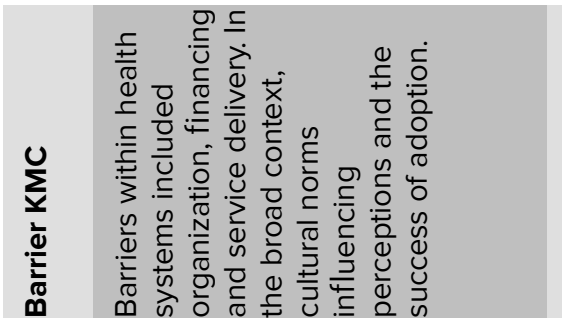
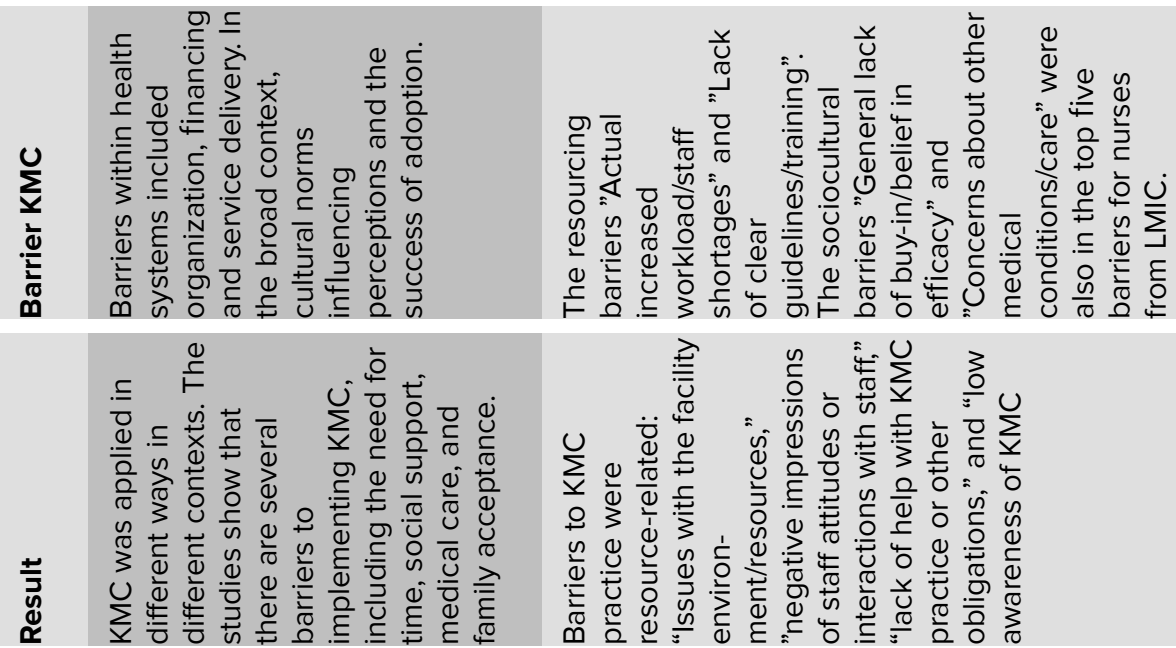





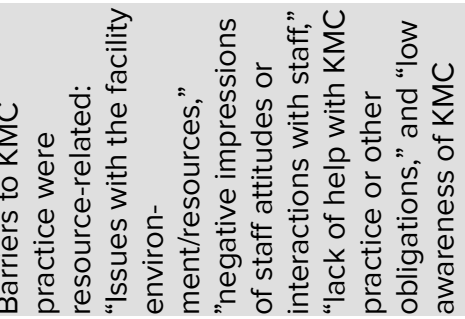

됴

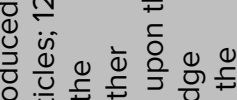



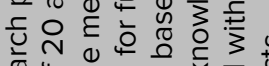

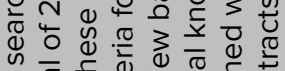

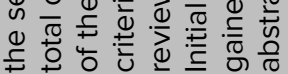

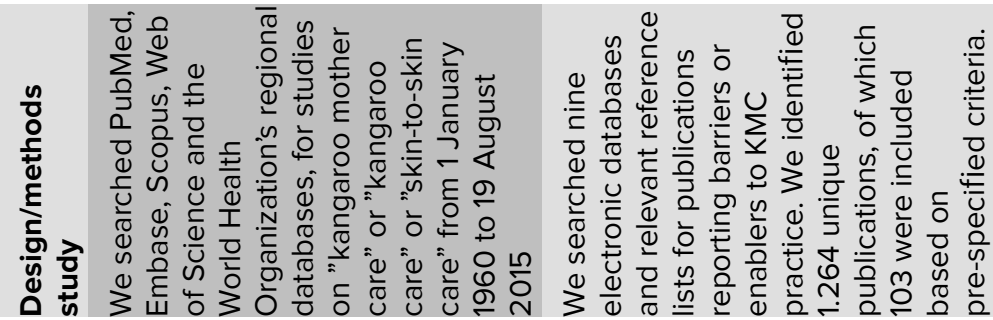
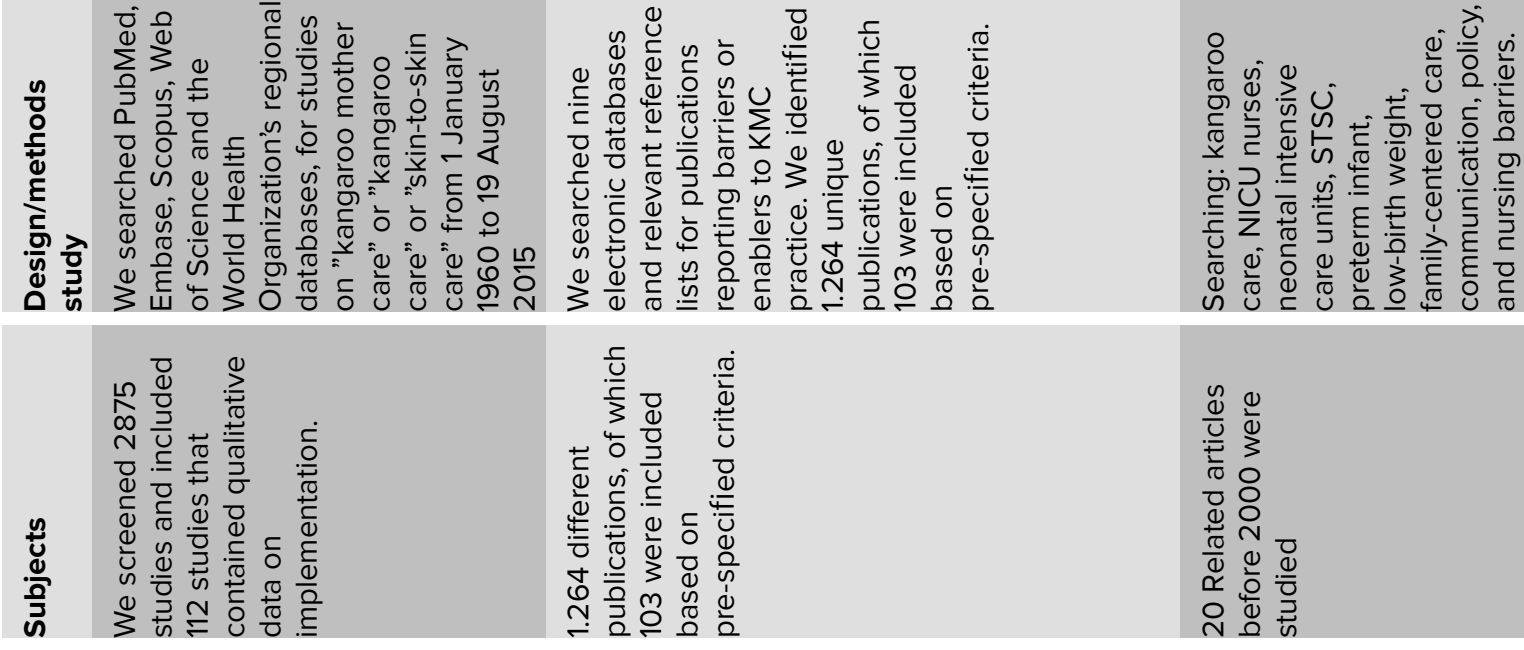

\begin{tabular}{|c|}
\hline 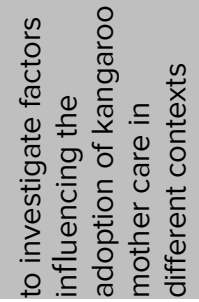 \\
\hline
\end{tabular}



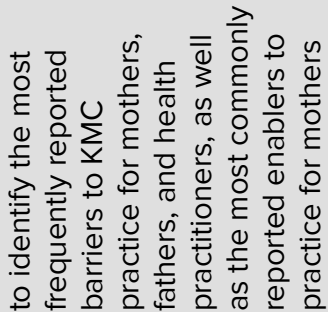
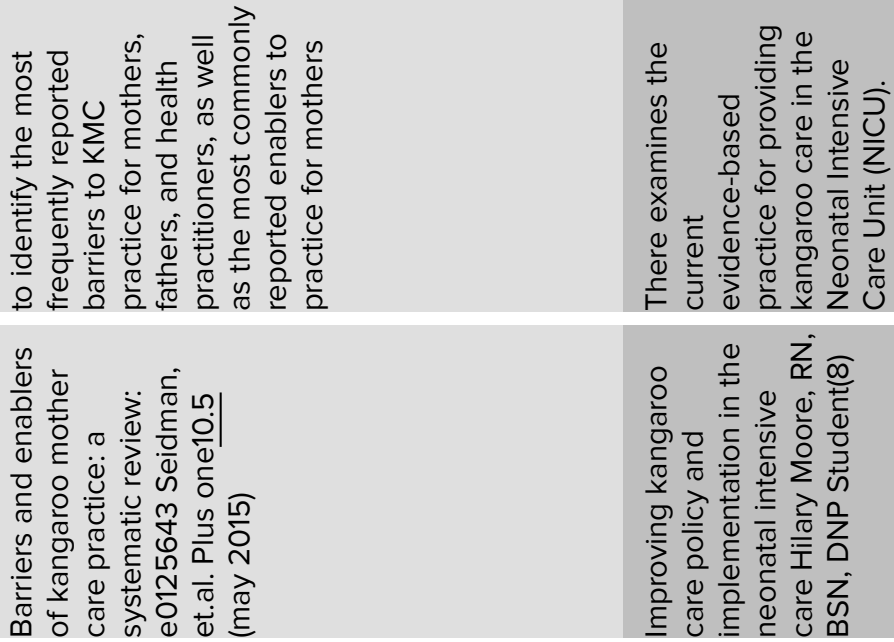

\begin{tabular}{|c|}
\hline 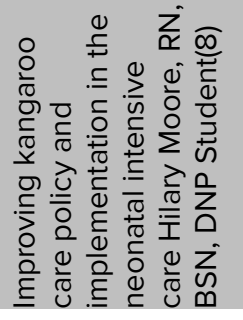 \\
\hline
\end{tabular}




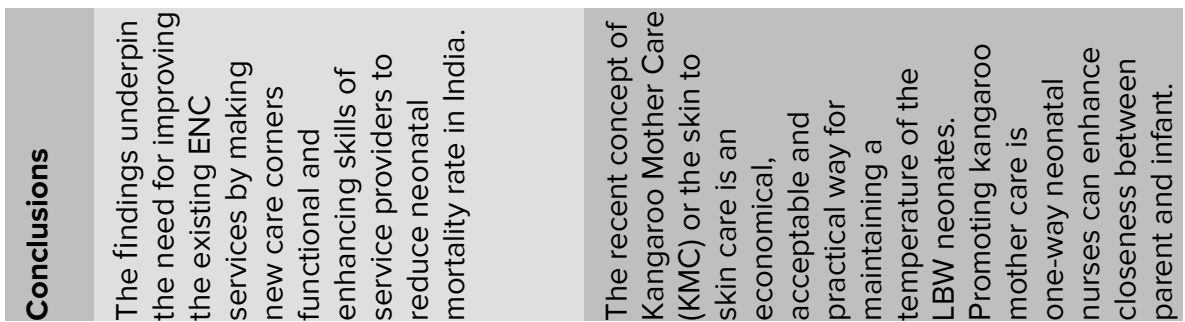

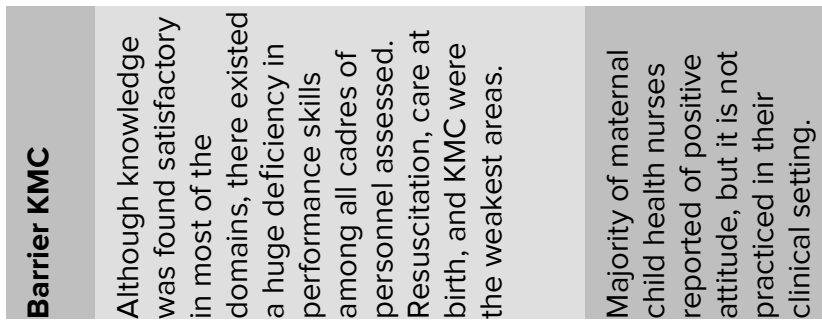


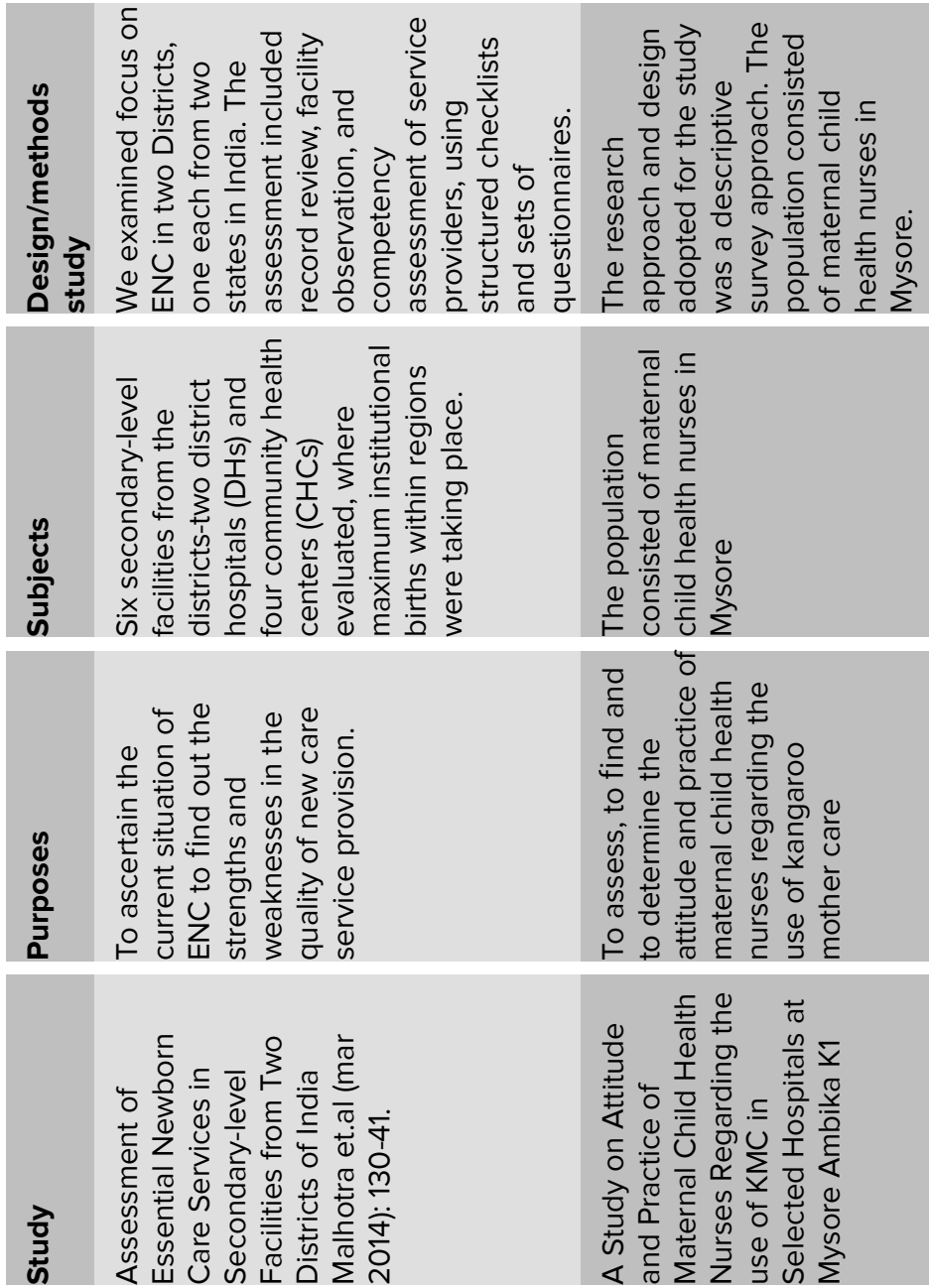


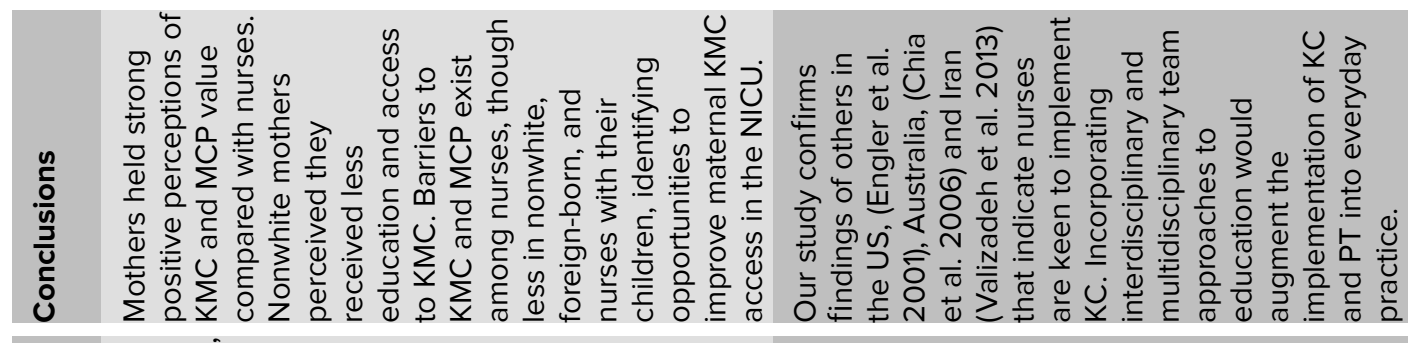

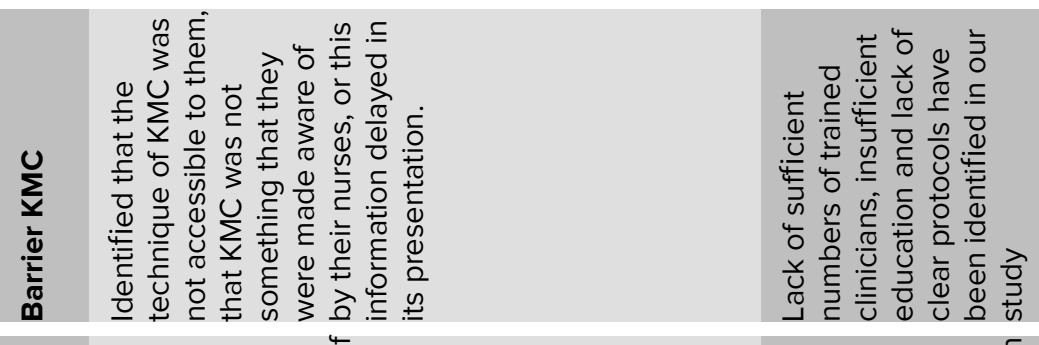



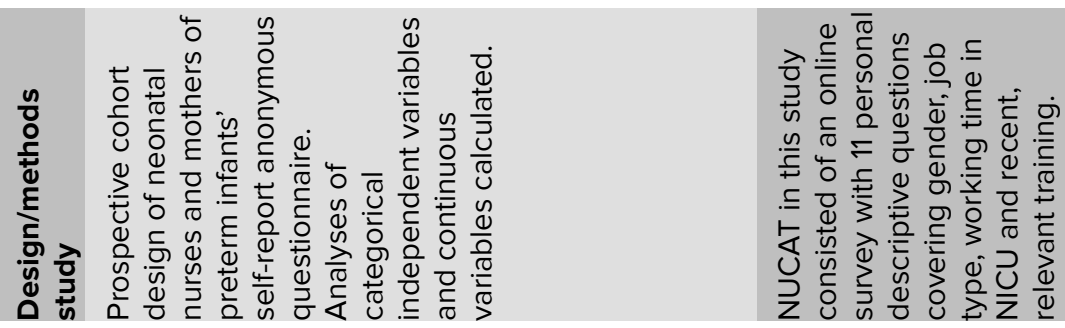
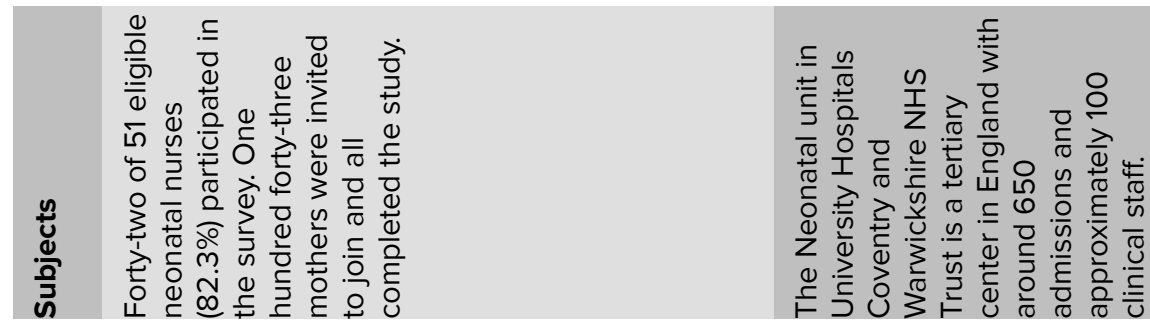

\begin{tabular}{|c|c|}
\hline  & 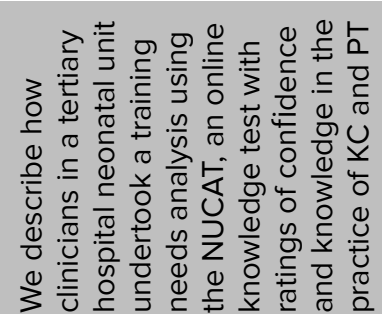 \\
\hline
\end{tabular}

\begin{tabular}{|c|c|}
\hline  &  \\
\hline
\end{tabular}




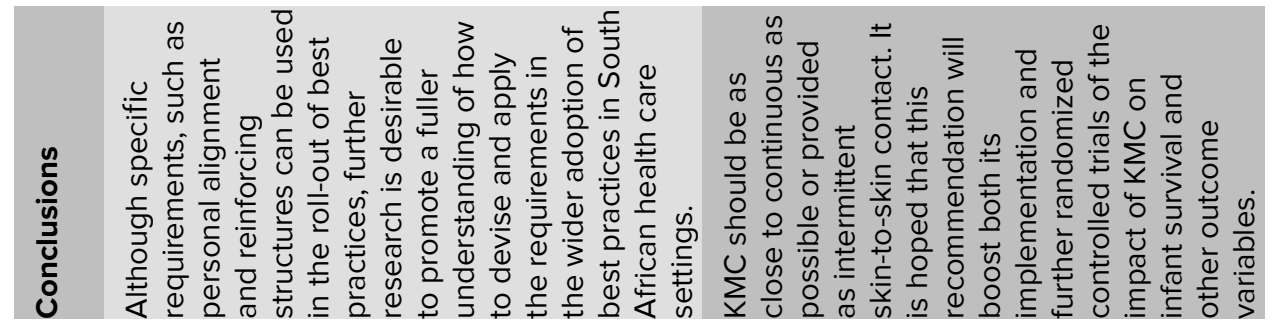

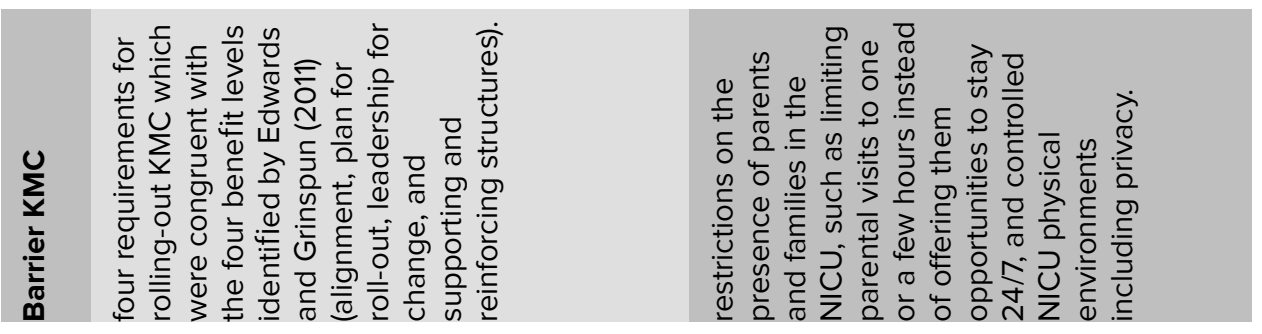

\begin{tabular}{|c|c|}
\hline 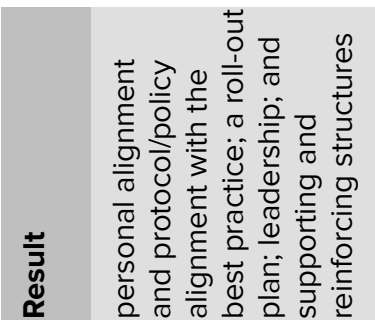 & 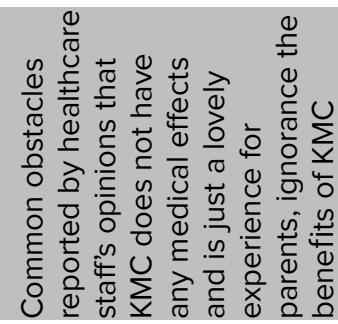 \\
\hline
\end{tabular}

\begin{tabular}{|c|c|c|}
\hline  &  &  \\
\hline
\end{tabular}

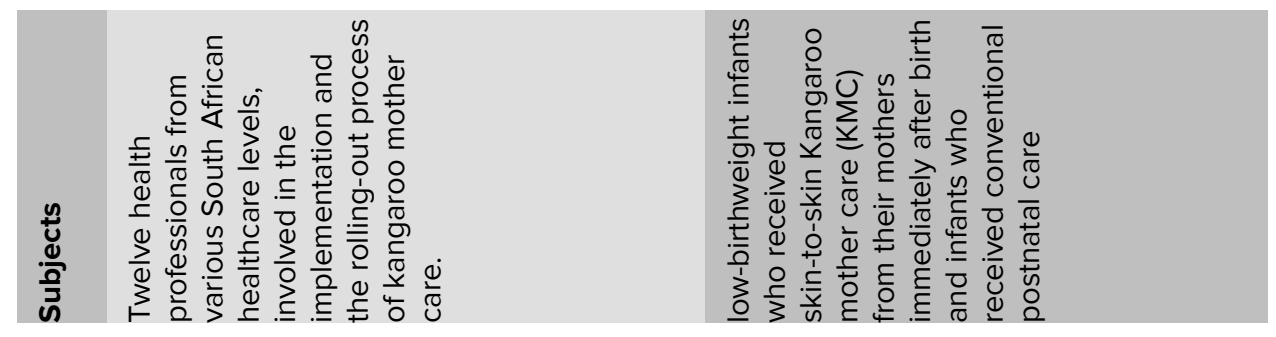

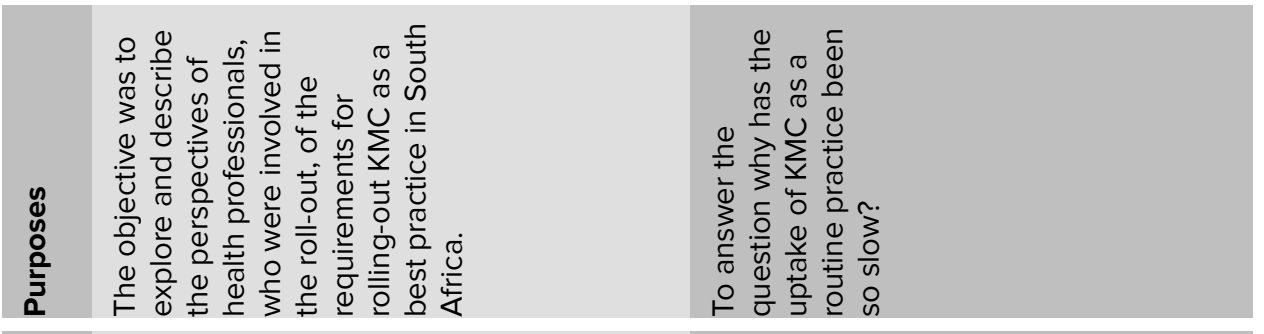








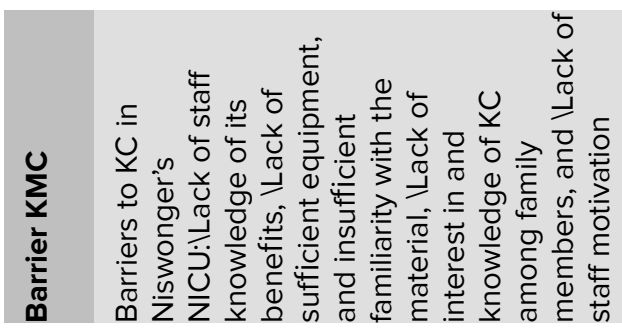



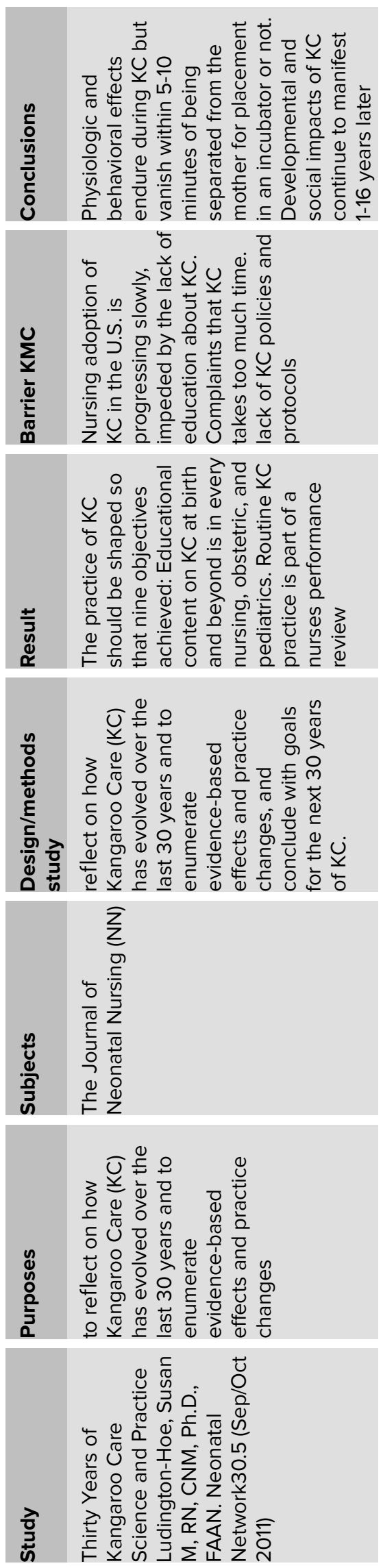



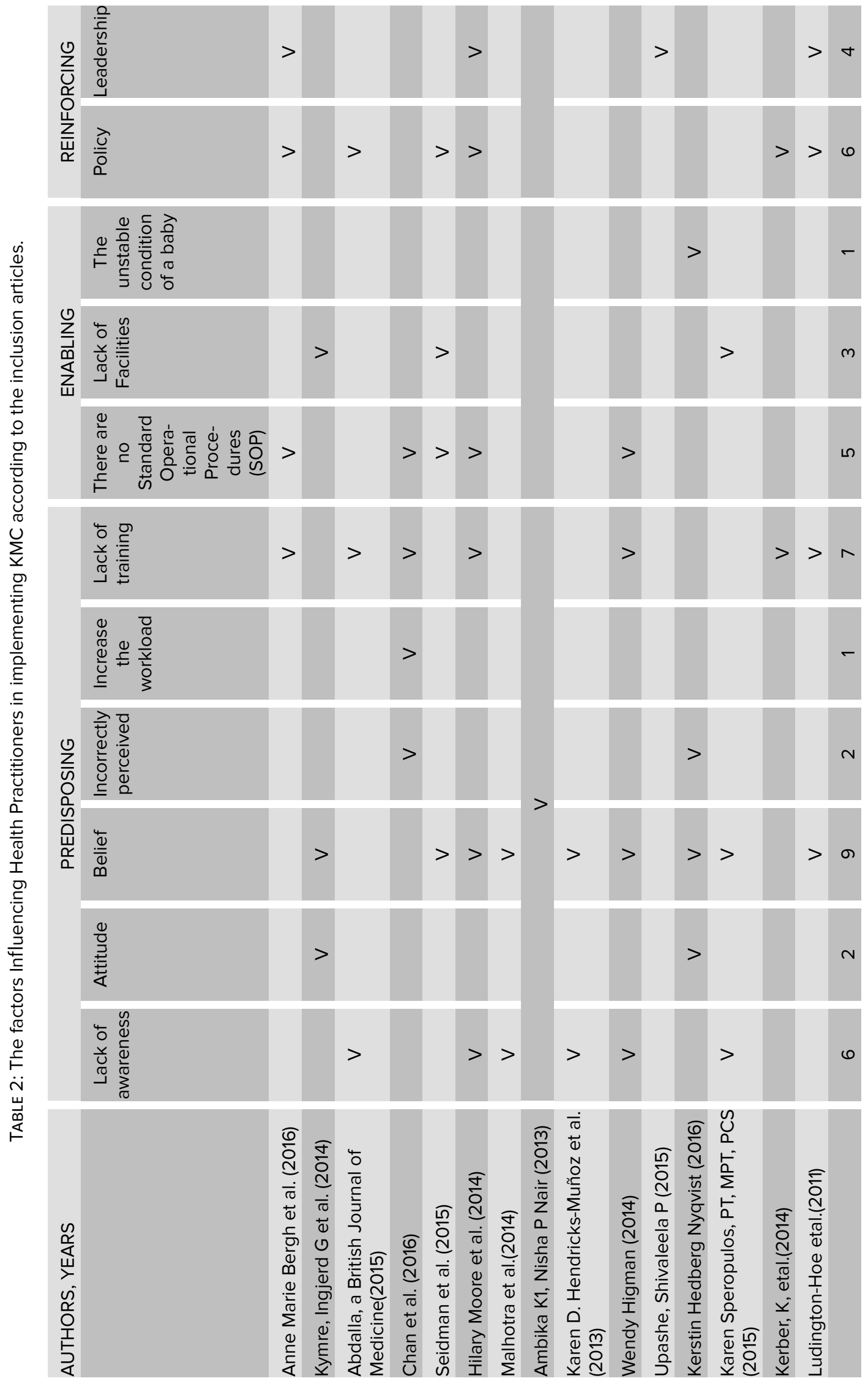


\section{Discussion}

We identified and classified factors influencing nurses in implementing kangaroo care according to the green model: (i) predisposing factors: the attitude of nurses is ambivalent, lack of knowledge and belief (iii) enabling factors: lack of infrastructure, the physiological stability baby, standard operational procedures, and lack of skills, (iii) reinforcing elements: institutional leadership and lack of regulatory / policy.

\subsection{Predisposing factors}

The attitude of NICU nurses in the practice of KMC is ambivalent. The nurses know the benefits of KMC and want to implement it as often as possible. But "as often as possible" is a concept that is broad and diverse, and their attitude was ambivalent concerning not always facilitate what they perceived as the optimal conditions. The ambivalent attitude of nurses can be seen with the restrictions they place on the visits by parents and families in the NICU, such as limiting parent visits to one or a few hours, instead of offering them a chance to live, visit the mother is restricted in the NICU, facilities do not meet the needs of older people, including privacy (Gabriel Seidman et al. 2015; Bergh et al. 2016).

Studies conducted by Nyqvist (2016) identify their indifference and even resistance to KMC from health practitioners. Common obstacles faced is the wrong opinion that KMC has no medical effect and just a nice experience for parents (mother), ignorance about the benefits of KMC for the baby and the family, the perception that KMC is an alternative method for the poor (Cong et al. 2013), and increasing the workload and safety risks associated with infant's health(Gabriel Seidman et al. 2015; Kymre n.d.).In fact, parents who actively supported to participate in the care of their babies, including KMC from the actual birth can ease the workload of nurses (Kymre n.d.)

Inconsistent practices and lack of belief in kangaroo mother care and limited knowledge of such care restricted its uptake among health practitioner. When an infant is born prematurely, the NICU nurses need to be an advocate for both mother and infant. To empower the NICU nurses towards kangaroo care practice improvement, discussing the importance of their advocacy role is necessary. After the NICU nurses can identify his or her role, willingness to change and participate will develop. However, it has proven that optimal kangaroo care implementation rates cannot be met without a standard policy. 


\subsection{Enabling factors}

Research conducted by Moore et al. (2014) identified the factors that affect the implementation of the KMC as the reluctance of management of health care providers to allocate a particular space, the beds were comfortable, and the food and do not rearrange staff schedules to allow the KMC. The lack of standard operating procedures and a shortage of staff, as well as staff change-instead, become an obstacle to the implementation of the KMC or Perawatan Metode Kanguru (PMK). On the other hand, successful implementation of KMC reported having the support of management and good communication among staff.

Concerns healthcare practitioners' instability physiological baby-related loss of temperature and worries babies become stressed due to transfer in and out of the KMC. Condition physiological stability infant should be checked intensively before being given the $\mathrm{KMC}$, a series of tests given time to consume and increases hesitations power to conduct KMC.

Although the implementation of the program conducted comprehensively, KMC practices identified sustainability as a challenge.

\subsection{Reinforcing factor}

Many studies have shown the positive effects of KMC in infants and families. At all levels of NICU care, KMC should be included as a core component of the standard of care continuity in the NICU. WHO has recommended that the KMC should provide routine care of newborns weighing up to 2000 grams at birth and should begin immediately after the baby is clinically stable.

Research conducted by Bergh et al. (2016) identifies professional resistance and a lack of political priority for newborns and care of low birth weight in the political structure and health at the beginning of KMC introduced to the health facility. When the institutional leadership does not prioritize kangaroo care resulting health practitioners are less motivated to practice or teach PMK to Mother. Although KMC has been included in the global health agenda as one of the critical interventions for the reduction of mortality of newborns, we expect the majority to follow. However, this expectation may not be realized without the support of the country's leadership and a transparent and integrated approach to improve KMC strategies for detailed operational planning and budgeting. 


\section{Conclusions}

Encourage mothers to do kangaroo care method (Perawatan Metode Kanguru/ (PMK) or Kangaroo Mother Care (PMC) requires support from various parties, including from health personnel. Increased PMK is not a natural process, and it takes time to do the service integrated into a newborn care package. Many factors affect the health workers in implementing the KMC: an ambivalent attitude of nurses, lack of knowledge, belief, lack of infrastructure, the physiological stability baby, lack of standard operational procedures, lack of skills, institutional leadership and lack of policy. Three of the topranked factors influencing KMC practice for nurses were: belief, lack of system and lack of standard operational procedures (SOP).

\section{References}

[1] Abdalla, aa, and E a H M Ali. 2015. "Barriers to Implementation of Facility-Based Kangaroo Mother Care for Pre-Term and Low Birth Weight Infants in River Nile State, Sudan; 2014." British Journal of Medicine and Medical Research 9 (4): BJMMR-18741. doi:10.9734/BJMMR/2015/18741.

[2] Ambika, K, and Nisha P Nair. 2013. "A Study on Attitude and Practice of Maternal Child Health Nurses Regarding the Use of Kangaroo Mother Care in Selected Hospitals at Mysore." International Journal of Nursing Care 1 (1). New Delhi: Institute of Medico-Legal Publications: 1-4. http://search.proquest.com/docview/ 1370349589 ? accountid=17242.

[3] Bergh, A.-M., J De Graft-Johnson, N Khadka, A Om'Iniabohs, R Udani, H Pratomo, and S De Leon-Mendoza. 2016. "The Three Waves in Implementation of Facility-Based Kangaroo Mother Care: A Multi-Country Case Study from Asia." BMC International Health and Human Rights 16 (1). MRC Unit for Maternal and Infant Health Care Strategies, University of Pretoria, Pretoria, South Africa. doi:10.1186/s12914-016-00804.

[4] Chan, Grace J grace chan hsph Harvard edu, Amy S Labar, Stephen Wall, and Rifat Atuna. 2016. "Kangaroo Mother Care: A Systematic Review of Barriers and Enablers." Метод «Кенгуру»: Систематический Обзор Барьеров И Способствующих Факторов. 94 (2): 130-41. doi:10.2471/BLT.15.157818.

[5] Cong, Xiaomei, Susan Ludington-Hoe, Victoria Vazquez, Di Zhang, and Sharon Zaffetti. 2013. "Ergonomic Procedure for Heel Sticks and Shots in Kangaroo Care (Skin-to-Skin) Position." Neonatal Network冈: NN 32 (5): 353-57. doi:10.1891/07300832.32.5.353. 
[6] Engmann, Cyril, Stephen Wall, Gary Darmstadt, Bina Valsangkar, and Mariam Claeson. 2013. "Consensus on Kangaroo Mother Care Acceleration." The Lancet 382 (9907). London: Elsevier Limited: e26-7. doi:http://dx.doi.org/10.1016/S01406736(13)62293-X.

[7] Higman, Wendy, Louise M. Wallace, Susan Law, Naomi C. Bartle, and Kathryn Blake. 2015. “Assessing Clinicians' Knowledge and Confidence to Perform Kangaroo Care and Positive Touch in a Tertiary Neonatal Unit in England Using the Neonatal Unit Clinician Assessment Tool (NUCAT)." Journal of Neonatal Nursing 21 (2). Elsevier Ltd: 72-82. doi:10.1016/j.jnn.2014.09.001.

[8] Kymre, I G, 2014. n.d. "NICU Nurses ' Ambivalent Attitudes in Skin- to-Skin Care Practice" 288.

[9] Ludington-Hoe RN, CNM, Ph.D., FAAN, Susan M. 2011. "Thirty Years of Kangaroo Care Science and Practice." Neonatal Network 30 (5). New York: Springer Publishing Company: 357-62. http://search. proquest.com/docview/885237752 ?accountid=17242.

[10] Malhotra, S, S P Zodpey, A L Vidyasagaran, K Sharma, S S Raj, S B Neogi, $G$ Pathak, and A Saraf. 2014. "Assessment of Essential Newborn Care Services in Secondary-Level Facilities from Two Districts of India." Journal of Health, Population and Nutrition 32 (1). All India Institute of Medical Sciences, New Delhi, India: 130-41. https://www.scopus.com/inward/record.uri?eid=2-s2.084902656775\&partnerID=40\&md5=4c84aa6959d6edf161a343f6030f2d1d.

[11] Nyqvist, Kerstin H edberg. 2016. "Given the Benefits of Kangaroo Mother Care, Why Has Its Routine Uptake Been so Slow?” Acta Paediatrica (Oslo, Norway区: 1992) 105 (4): 341-42. doi:10.1111/apa.13236.

[12] Seidman, Gabriel, Shalini Unnikrishnan, Emma Kenny, Scott Myslinski, Sarah Cairns-Smith, Brian Mulligan, and Cyril Engmann. 2015. "Barriers and Enablers of Kangaroo Mother Care Practice: A Systematic Review." PLoS ONE 10 (5): 1-21. doi:10.1371/journal.pone.0125643.

[13] Seidman, G, S Unnikrishnan, E Kenny, S Myslinski, S Cairns-Smith, B Mulligan, and C Engmann. 2015. "Kangaroo Mother Care: A Systematic Review of Barriers and Enablers.” PLoS One 10 (5): e0125643. doi:10.1371/journal.pone.0125643.

[14] Seidman Unnikrishnan, et.al. S., Kenny, E., Myslinski, S., Cairns-Smith, S., Mulligan, B. and Engmann, C, G. 2015. "Barriers and Enablers of Kangaroo Mother Care Practice: A Systematic Review." PLoS One.

[15] UNICEF. 2014. "Levels \& Trends in Child Mortality, Report 2014," 1. http://www.who. int/maternal_child_adolescent/documents/levels_trends_child_mortality_2014/en/. 